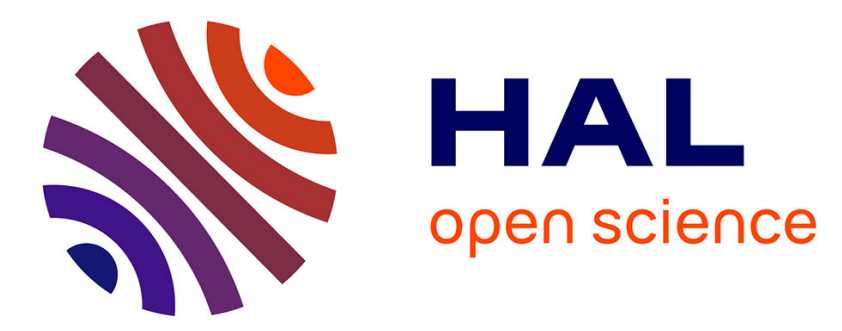

\title{
Bottom-up modeling of $\mathrm{Al} / \mathrm{Ni}$ multilayer combustion: Effect of intermixing and role of vacancy defects on the ignition process
}

\author{
Anne Hémeryck, Jean-Marie Ducéré, Cloé Lanthony, Alain Estève, Carole \\ Rossi, Mehdi Djafari-Rouhani, Daniel Estève
}

\section{To cite this version:}

Anne Hémeryck, Jean-Marie Ducéré, Cloé Lanthony, Alain Estève, Carole Rossi, et al.. Bottomup modeling of $\mathrm{Al} / \mathrm{Ni}$ multilayer combustion: Effect of intermixing and role of vacancy defects on the ignition process. Journal of Applied Physics, 2013, 113 (20), pp.204301. 10.1063/1.4807164 . hal-01496631

\section{HAL Id: hal-01496631 \\ https://hal.laas.fr/hal-01496631}

Submitted on 27 Mar 2017

HAL is a multi-disciplinary open access archive for the deposit and dissemination of scientific research documents, whether they are published or not. The documents may come from teaching and research institutions in France or abroad, or from public or private research centers.
L'archive ouverte pluridisciplinaire HAL, est destinée au dépôt et à la diffusion de documents scientifiques de niveau recherche, publiés ou non, émanant des établissements d'enseignement et de recherche français ou étrangers, des laboratoires publics ou privés. 


\section{AIP Applied Physics}

\section{Bottom-up modeling of Al/Ni multilayer combustion: Effect of intermixing and role of vacancy defects on the ignition process}

A. Hemeryck, J.-M. Ducéré, C. Lanthony, A. Estève, C. Rossi et al.

Citation: J. Appl. Phys. 113, 204301 (2013); doi: 10.1063/1.4807164

View online: http://dx.doi.org/10.1063/1.4807164

View Table of Contents: http://jap.aip.org/resource/1/JAPIAU/v113/i20

Published by the American Institute of Physics.

\section{Additional information on J. Appl. Phys.}

Journal Homepage: http://jap.aip.org/

Journal Information: http://jap.aip.org/about/about_the_journal

Top downloads: http://jap.aip.org/features/most_downloaded

Information for Authors: http://jap.aip.org/authors

\section{ADVERTISEMENT}

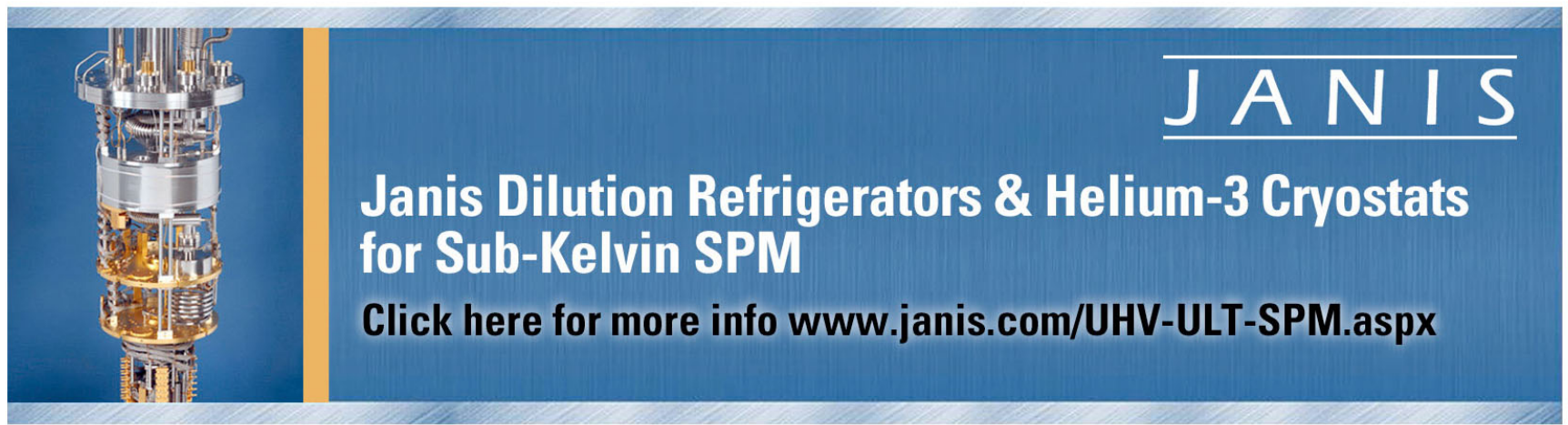




\title{
Bottom-up modeling of Al/Ni multilayer combustion: Effect of intermixing and role of vacancy defects on the ignition process
}

\author{
A. Hemeryck, ${ }^{1,2, a)} \mathrm{J}_{-}-\mathrm{M}$. Ducéré, ${ }^{1,2} \mathrm{C}_{\text {. Lanthony, }}{ }^{1,3}$ A. Estève, ${ }^{1,2, \mathrm{~b})} \mathrm{C}$. Rossi, ${ }^{1,2}$ \\ M. Djafari-Rouhani, ${ }^{1,3}$ and D. Estève ${ }^{1,2}$ \\ ${ }^{1}$ CNRS, LAAS, 7 Avenue du Colonel Roche, F-31400 Toulouse, France \\ ${ }^{2}$ Univ de Toulouse, LAAS, F-31400 Toulouse, France \\ ${ }^{3}$ Univ de Toulouse, UPS, LAAS, F-31400 Toulouse, France
}

(Received 8 January 2013; accepted 2 May 2013; published online 22 May 2013)

\begin{abstract}
Vapor deposited multilayered aluminum/oxide and bimetallics are promising materials for Micro Electro Mechanical System technologies as energy carriers, for instance, microinitiators or heat microsources in biological or chemical applications. Among these materials, the Al/Ni couple has received much attention both experimentally and theoretically. However, the detailed relation between the chemical composition of the intermixed interfacial regions and its impact on the ignition capabilities remains elusive. In this contribution, we propose a two-fold strategy combining atomistic density functional theory (DFT) calculations and a macroscopic 1D model of chemical kinetics. The DFT calculations allow the description of the elementary chemical processes (involving $\mathrm{Al}, \mathrm{Ni}$ atoms and vacancies basic ingredients) and to parameterize the macroscopic model, in which the system is described as a stack of infinite layers. This gives the temporal evolution of the system composition and temperature. We demonstrate that the amount of vacancies, originating from the deposition process and the $\mathrm{Al}$ and $\mathrm{Ni}$ lattice mismatch, plays a critical role on both the ignition time and the temperature. The presence of vacancies enhances the migration of atoms between layers and so dramatically speeds up the atomic mixing at low temperatures far below ignition temperature, also pointing to the relation between experimental deposition procedures and ageing of the nanolaminates. (C) 2013 AIP Publishing LLC.
\end{abstract}

[http://dx.doi.org/10.1063/1.4807164]

\section{INTRODUCTION}

Nanoenergetic materials can undergo highly exothermic self-sustained chemical reactions giving birth to a wide range of applications, both civilian and military, including environmentally safe and clean primers and detonators, smart and fast fuses, micro-soldering, nanoscale heat sources for biological and chemical neutralization, and disease treatment. ${ }^{1-12}$

Downscaling these materials in such a way to allow for "nanoenergetics on a chip" offers new perspectives in micro and nanosystems. ${ }^{13}$ Among these materials, vapor deposited multilayered thermites (metal/oxide) ${ }^{14-16}$ or bimetallics ${ }^{17,18}$ are promising integratable nanostructured materials for Micro Electro Mechanical Systems (MEMS). Many hundreds of nanometer thick layers can be stacked by alternating the basic ingredients (oxidizer and fuel for instance). Each reactant layer thickness can be accurately set at $\pm 5 \mathrm{~nm}$ (Ref. 15) and the layering also places the reactants in intimate contact leading to a reduction of the diffusion distance by a factor of 10-1000 compared to the same material traditionally prepared by powder mixing. ${ }^{19}$ As it rapidly occurred in microelectronics, drastic downscaling of the layers down to the nanometer scale poses the issue of the interfaces, their detailed structures and impact on the overall device

\footnotetext{
${ }^{\text {a) }}$ Author to whom correspondence should be addressed. Electronic mail: aanne.hemeryck@laas.fr. Tel.: +33 (0)5 613364 94. Fax: +33 (0)5 6133 6208 .

b)Electronic mail: aesteve@laas.fr. Tel.: +33 (0)5 613363 53. Fax: +33 (0)561336208.
}

operation (ignition time and temperature, ageing behavior). In this frame, the technological route to produce "atomically controlled" interfaces (thickness and atomic arrangement) is a major challenge of the future generation of "on a chip" integrated nanoenergetic materials.

This paper aims at giving preliminary clues and proposing new directions to better tackle the problem of simulating the thermal characteristics of multi-layers in connection to their structural properties. We propose a fully physicochemical based model of the ignition process based on a bottom-up multilevel modeling approach, from Density Functional Theory (DFT) calculations to an environment dependent rate equation formulation. Specifically, we focus this general approach on the ignition modeling of a $\mathrm{Al}-\mathrm{Ni}$ (1:1 ratio) bilayer; ${ }^{20}$ we study the intermixing and interface atomic composition under different temperatures, and analyze its impact on ignition properties.

$\mathrm{Al} / \mathrm{Ni}$ multilayer foils ${ }^{17-19,21-29}$ have been studied comprehensively over the past decade both theoretically and experimentally; their associated elementary chemistry is by far less complex than that of thermites where oxidoreduction mechanisms are also taking place. For all these reasons, $\mathrm{Al} / \mathrm{Ni}$ foils are suited as model systems for basic understanding and modeling purposes. The exothermic reaction is related to an atomic mixing between reactants $(\mathrm{Al}$ and $\mathrm{Ni}$ ) that initiates at the reactant interfaces. ${ }^{19,21,25,27,30}$ The relative role of thermal and mass diffusion, convection, and radiation as a function of layer nanostructures is now well documented, mostly experimentally., 19,22,27,31,32 Along this 
line, there is a consensus on the crucial role played by the specific atomic arrangement at the multiple stacking interfaces on the final material characteristics (ignition temperature, energy reservoir). Indeed, it is unanimously approved that overall mass transport after ignition is reduced by the presence of pre-existing inter-metallic interfaces generated during the deposition process between each layers. ${ }^{19}$ These so-called diffusion barriers or energetic barriers are thus necessary to avoid spontaneous ignition reactions. For this reason, there is a major interest in obtaining the key parameters that will make it possible to control the interface formation and composition during the process. Particularly, two questions are still to be solved: (1) how the barrier layers do fundamentally alter and affect the ignition process, through which atomistic mechanisms; and (ii) how can we predict the formation of barrier layers (composition, thicknesses) mandatory to the subsequent prediction of the optimal ignition conditions (temperature and delay). To address these issues, there is a need to develop new modeling strategies with the objective of designing virtually appropriate barrier layers, to arrive at a nanoenergetic material with tuned sensitivity and reactivity.

In what follows, we first present our modeling strategy including basic mechanisms identification through DFT calculations and subsequent mesoscale equation set. Importantly, we aimed at introducing explicitly the role of defects as the result of $\mathrm{Al} / \mathrm{Ni}$ lattices mismatch; in this seminal work, we only consider single vacancy defects as they represent the most elementary as well as the easier defect to be characterized by our DFT-based modeling approach. We demonstrate and characterize the role of defect presence on the ignition process that exhibits lowered ignition temperature. As a result of annealing sequences, we further investigate the key role of barrier layers on the ignition characteristics (temperature and delay) potentially illustrating the mechanisms of materials degradation over ageing. The paper first concentrates on the multilevel approach: We describe the $\mathrm{Al} / \mathrm{Ni}$ model system geometry and the methods. In a second part, we discuss the simulation results concerning both the role of vacancy defects and the preexisting barrier layers on the thermal stability of the system.

\section{DESCRIPTION OF THE MODEL}

Assuming that AlNi multilayer ignition is ruled by atomic mixing, we consider only the atomic diffusion along the direction normal to the layers. In this spirit, we have developed a one-dimensional model, with physical quantities averaged over the other two dimensions, in which species mix according to chemical kinetics. This mixing releases an energy that translates into a temperature increase, which, in turn, impacts on the kinetics, the overall temperature being able to dissipate. The external stimulus leading to the eventual ignition is taken as an applied temperature.

To describe the evolution of the system, we consider the diffusion of two species: the vacancies and atoms in interstitial position. Indeed, DFT calculations show that diffusion of atoms in lattice positions, without involving vacancies, is characterized by high activation barriers and appears as unlikely to happen for both components. To be effective, these mechanisms require the addition of a new one: the creation of interstitial-vacancy pairs (Frenkel pairs) and their recombination.

In order to quantify the rates and the energy release associated with each mechanism, we need to characterize the kinetics and thermodynamics of the reactions. This is performed at the atomic level within the framework of DFT. The atomic resolution of DFT calculations imposes an atomic resolution of the diffusion in the mesoscale model. Therefore, our model can be seen as a stack of uniform infinite atomic layers.

The so-defined model can be divided into three submodels: (1) a kinetic part for the time evolution of the system composition, (2) an energetic part for linking the composition to energetic parameters, and (3) a thermal part for translating energy changes into temperature changes.

\section{A. Kinetic sub-model}

This part of the model describes the evolution of the layer compositions. The considered species are the $\mathrm{Al}$ and $\mathrm{Ni}$ atoms in lattice position $(\mathrm{L}(\mathrm{Al})$ and $(\mathrm{L}(\mathrm{Ni}))$, the vacancies $(\mathrm{V})$ and the $\mathrm{Ni}$ atoms in interstitial position $(\mathrm{I}(\mathrm{Ni}))$. We ruled out the $\mathrm{Al}$ atoms in interstitial position because DFT calculations show, in all cases, that their formation is always unfavorable. The concentrations of the species evolve according to the following 6 reactions, where $\mathrm{i}$ indicates the layer in which the atomic scale reaction occurs:

$$
\begin{gathered}
\mathrm{L}(\mathrm{Al})_{\mathrm{i}}+\mathrm{V}_{\mathrm{i}+1} \leftrightarrow \mathrm{L}(\mathrm{Al})_{\mathrm{i}+1}+\mathrm{V}_{\mathrm{i}}, \\
\mathrm{L}(\mathrm{Ni})_{\mathrm{i}}+\mathrm{V}_{\mathrm{i}+1} \leftrightarrow \mathrm{L}(\mathrm{Ni})_{\mathrm{i}+1}+\mathrm{V}_{\mathrm{i}}, \\
\mathrm{I}(\mathrm{Ni})_{\mathrm{i}} \leftrightarrow \mathrm{I}(\mathrm{Ni})_{\mathrm{i}+1}, \\
\mathrm{~L}(\mathrm{Ni})_{\mathrm{i}} \leftrightarrow \mathrm{I}(\mathrm{Ni})_{\mathrm{i}}+\mathrm{V}_{\mathrm{i}}, \\
\mathrm{L}(\mathrm{Ni})_{\mathrm{i}} \leftrightarrow \mathrm{I}(\mathrm{Ni})_{\mathrm{i}+1}+\mathrm{V}_{\mathrm{i}}, \\
\mathrm{L}(\mathrm{Ni})_{\mathrm{i}} \leftrightarrow \mathrm{I}(\mathrm{Ni})_{\mathrm{i}-1}+\mathrm{V}_{\mathrm{i}} .
\end{gathered}
$$

Here $\mathrm{L}(\mathrm{Al})_{\mathrm{i}}$ refers to lattice aluminum in the ith layer and so on for others species. Reactions 1 and 2 describe the migration of vacancies towards $\mathrm{Al}$ and Ni lattice atoms, respectively. Reaction 3 describes the migration of Ni interstitials and reactions 4 to 6 describe the creation and recombination of Frenkel pairs.

Having defined the above set of chemical reactions, the time evolution is described by the following set of $4 \times n_{\text {layer }}$ differential equations (four species per layer), taking these reactions into account:

$$
\begin{aligned}
\frac{\mathrm{d}\left[\mathrm{L}(\mathrm{Al})_{\mathrm{i}}\right]}{\mathrm{dt}}= & -\mathrm{k}_{+1, \mathrm{i}}\left[\mathrm{L}(\mathrm{Al})_{\mathrm{i}}\right]\left[\mathrm{V}_{\mathrm{i}+1}\right]+\mathrm{k}_{-1, \mathrm{i}}\left[\mathrm{L}(\mathrm{Al})_{\mathrm{i}+1}\right]\left[\mathrm{V}_{\mathrm{i}}\right] \\
& +\mathrm{k}_{+1, \mathrm{i}-1}\left[\mathrm{~L}(\mathrm{Al})_{\mathrm{i}-1}\right]\left[\mathrm{V}_{\mathrm{i}}\right]-\mathrm{k}_{-1, \mathrm{i}-1}\left[\mathrm{~L}(\mathrm{Al})_{\mathrm{i}}\right]\left[\mathrm{V}_{\mathrm{i}-1}\right]
\end{aligned}
$$




$$
\begin{aligned}
& \frac{\mathrm{d}\left[\mathrm{L}(\mathrm{Ni})_{\mathrm{i}}\right]}{\mathrm{dt}}=-\mathrm{k}_{+2, \mathrm{i}}\left[\mathrm{L}(\mathrm{Ni})_{\mathrm{i}}\right]\left[\mathrm{V}_{\mathrm{i}+1}\right]+\mathrm{k}_{-2, \mathrm{i}}\left[\mathrm{L}(\mathrm{Ni})_{\mathrm{i}+1}\right]\left[\mathrm{V}_{\mathrm{i}}\right] \\
& +\mathrm{k}_{+2, \mathrm{i}-1}\left[\mathrm{~L}(\mathrm{Ni})_{\mathrm{i}-1}\right]\left[\mathrm{V}_{\mathrm{i}}\right]-\mathrm{k}_{-2, \mathrm{i}-1}\left[\mathrm{~L}(\mathrm{Ni})_{\mathrm{i}}\right]\left[\mathrm{V}_{\mathrm{i}-1}\right] \\
& -\mathrm{k}_{+4, \mathrm{i}}\left[\mathrm{L}(\mathrm{Ni})_{\mathrm{i}}\right]+\mathrm{k}_{-4, \mathrm{i}}\left[\mathrm{V}_{\mathrm{i}}\right]\left[\mathrm{I}(\mathrm{Ni})_{\mathrm{i}}\right] \\
& -\mathrm{k}_{+5, \mathrm{i}}\left[\mathrm{L}(\mathrm{Ni})_{\mathrm{i}}\right]+\mathrm{k}_{-5, \mathrm{i}}\left[\mathrm{V}_{\mathrm{i}}\right]\left[\mathrm{I}(\mathrm{Ni})_{\mathrm{i}+1}\right] \\
& -\mathrm{k}_{+6, \mathrm{i}}\left[\mathrm{L}(\mathrm{Ni})_{\mathrm{i}}\right]+\mathrm{k}_{-6, \mathrm{i}}\left[\mathrm{V}_{\mathrm{i}}\right]\left[\mathrm{I}(\mathrm{Ni})_{\mathrm{i}-1}\right] \text {, } \\
& \frac{\mathrm{d}\left[\mathrm{I}(\mathrm{Ni})_{\mathrm{i}}\right]}{\mathrm{dt}}=-\mathrm{k}_{+3, \mathrm{i}}\left[\mathrm{I}(\mathrm{Ni})_{\mathrm{i}}\right]+\mathrm{k}_{-3, \mathrm{i}}\left[\mathrm{I}(\mathrm{Ni})_{\mathrm{i}+1}\right] \\
& +\mathrm{k}_{+3, \mathrm{i}-1}\left[\mathrm{I}(\mathrm{Ni})_{\mathrm{i}-1}\right]+\mathrm{k}_{-3, \mathrm{i}-1}\left[\mathrm{I}(\mathrm{Ni})_{\mathrm{i}}\right] \\
& +\mathrm{k}_{+4, \mathrm{i}}\left[\mathrm{L}(\mathrm{Ni})_{\mathrm{i}}\right]-\mathrm{k}_{-4, \mathrm{i}}\left[\mathrm{V}_{\mathrm{i}}\right]\left[\mathrm{I}(\mathrm{Ni})_{\mathrm{i}}\right] \\
& +\mathrm{k}_{+5, \mathrm{i}-1}\left[\mathrm{~L}(\mathrm{Ni})_{\mathrm{i}-1}\right]-\mathrm{k}_{-5, \mathrm{i}-1}\left[\mathrm{~V}_{\mathrm{i}-1}\right]\left[\mathrm{I}(\mathrm{Ni})_{\mathrm{i}}\right] \\
& +\mathrm{k}_{+6, \mathrm{i}+1}\left[\mathrm{~L}(\mathrm{Ni})_{\mathrm{i}+1}\right]-\mathrm{k}_{-6, \mathrm{i}+1}\left[\mathrm{~V}_{\mathrm{i}+1}\right]\left[\mathrm{I}(\mathrm{Ni})_{\mathrm{i}}\right], \\
& \frac{\mathrm{d}\left[\mathrm{V}_{\mathrm{i}}\right]}{\mathrm{dt}}=\mathrm{k}_{+1, \mathrm{i}}\left[\mathrm{L}(\mathrm{Al})_{\mathrm{i}}\right]\left[\mathrm{V}_{\mathrm{i}+1}\right]-\mathrm{k}_{-1, \mathrm{i}}\left[\mathrm{L}(\mathrm{Al})_{\mathrm{i}+1}\right]\left[\mathrm{V}_{\mathrm{i}}\right] \\
& -\mathrm{k}_{+1, \mathrm{i}-1}\left[\mathrm{~L}(\mathrm{Al})_{\mathrm{i}-1}\right]\left[\mathrm{V}_{\mathrm{i}}\right]+\mathrm{k}_{-1, \mathrm{i}-1}\left[\mathrm{~L}(\mathrm{Al})_{\mathrm{i}}\right]\left[\mathrm{V}_{\mathrm{i}-1}\right] \\
& +\mathrm{k}_{+2, \mathrm{i}}\left[\mathrm{L}(\mathrm{Ni})_{\mathrm{i}}\right]\left[\mathrm{V}_{\mathrm{i}+1}\right]-\mathrm{k}_{-2, \mathrm{i}}\left[\mathrm{L}(\mathrm{Ni})_{\mathrm{i}+1}\right]\left[\mathrm{V}_{\mathrm{i}}\right] \\
& -\mathrm{k}_{+2, \mathrm{i}-1}\left[\mathrm{~L}(\mathrm{Ni})_{\mathrm{i}-1}\right]\left[\mathrm{V}_{\mathrm{i}}\right]+\mathrm{k}_{-2, \mathrm{i}-1}\left[\mathrm{~L}(\mathrm{Ni})_{\mathrm{i}}\right]\left[\mathrm{V}_{\mathrm{i}-1}\right] \\
& +\mathrm{k}_{+4, \mathrm{i}}\left[\mathrm{L}(\mathrm{Ni})_{\mathrm{i}}\right]-\mathrm{k}_{-4, \mathrm{i}}\left[\mathrm{V}_{\mathrm{i}}\right]\left[\mathrm{I}(\mathrm{Ni})_{\mathrm{i}}\right] \\
& +\mathrm{k}_{+5, \mathrm{i}}\left[\mathrm{L}(\mathrm{Ni})_{\mathrm{i}}\right]-\mathrm{k}_{-5, \mathrm{i}}\left[\mathrm{V}_{\mathrm{i}}\right]\left[\mathrm{I}(\mathrm{Ni})_{\mathrm{i}+1}\right] \\
& +\mathrm{k}_{+6, \mathrm{i}}\left[\mathrm{L}(\mathrm{Ni})_{\mathrm{i}}\right]-\mathrm{k}_{-6, \mathrm{i}}\left[\mathrm{V}_{\mathrm{i}}\right]\left[\mathrm{I}(\mathrm{Ni})_{\mathrm{i}-1}\right] \text {. }
\end{aligned}
$$

Here $\left[\mathrm{L}(\mathrm{Al})_{\mathrm{i}}\right]$ is the $\mathrm{L}(\mathrm{Al})$ concentration in the ith layer. $\mathrm{k}_{+\mathrm{j}, \mathrm{i}}$ and $\mathrm{k}_{-\mathrm{j}, \mathrm{i}}$ refer, respectively, to the rate constants associated with the forward and backward reaction $\mathrm{j}$ (described above) in the ith layer. Each rate constant is calculated as a function of the layer composition introducing an environment dependency for each chemical reaction throughout the stacking layers. Their determination is obtained via DFT calculations and detailed in the following part.

\section{B. Energetic sub-model}

An energetic model is implemented in order to introduce an explicit dependency of the atomic scale mechanisms as a function of the layer composition. This is the part of the model that relates the composition and the energetic parameters. It is used to calculate the activation energies, rate constants, and energy released during the last time step.

The total energy of the system is calculated as the sum of each layer energy contribution. The energy of a layer is itself defined as the sum of its components energies

$$
\begin{gathered}
\mathrm{E}_{\text {system }}=\sum \mathrm{E}_{\text {layer }}, \\
\mathrm{E}_{\text {layer }}=[\mathrm{L}(\mathrm{Al})] \times \mathrm{E}_{\mathrm{Al}}+[\mathrm{L}(\mathrm{Ni})] \times \mathrm{E}_{\mathrm{Ni}} \\
+([\mathrm{L}(\mathrm{Al})]+[\mathrm{L}(\mathrm{Ni})]) \times \mathrm{E}_{\mathrm{Mix}}(\mathrm{x}) \\
+[\mathrm{I}(\mathrm{Ni})] \times \mathrm{E}_{\mathrm{INi}}(\mathrm{x})+[\mathrm{V}] \times \mathrm{E}_{\mathrm{V}}(\mathrm{x}),
\end{gathered}
$$

where $\mathrm{E}_{\mathrm{Al}}$ and $\mathrm{E}_{\mathrm{Ni}}$ are the energies of an $\mathrm{Al}$ and a $\mathrm{Ni}$ atom, respectively; $\mathrm{E}_{\mathrm{Mix}}, \mathrm{E}_{\mathrm{INi}}$, and $\mathrm{E}_{\mathrm{V}}$ are, respectively, the mixing energy, the energy of an interstitial and the energy of a vacancy, as a function of the composition $\mathrm{x}$, the relative amount of $\mathrm{L}(\mathrm{Ni})$ in the layer, defined as

$$
\mathrm{x}=\frac{[\mathrm{L}(\mathrm{Ni})]}{[\mathrm{L}(\mathrm{Al})]+[\mathrm{L}(\mathrm{Ni})]}
$$

These functions are determined by DFT calculations, as described in Section III B and in Tables I and II.

According to the transition state theory, all of the reactions are associated with two activation energies (forward and backward) that allow, knowing the temperature, to calculate the rate constants

$$
\mathrm{k}=v \exp \left(\frac{-\Delta \mathrm{G}^{\ddagger}}{\mathrm{k}_{\mathrm{B}} \mathrm{T}}\right)
$$

where $v$ is the attempt vibration frequency, $\mathrm{k}_{\mathrm{B}}$ the Boltzmann constant, $T$ the absolute temperature, and $\Delta \mathrm{G}^{\ddagger}$ the Gibbs energy of activation. At the high temperature limit, the entropy term can be easily evaluated and one ends up with the Eyring law

$$
\mathrm{k}=\frac{\mathrm{k}_{\mathrm{B}} \mathrm{T}}{\mathrm{h}} \exp \left(\frac{-\mathrm{E}_{\mathrm{a}}}{\mathrm{k}_{\mathrm{B}} \mathrm{T}}\right),
$$

where $\mathrm{h}$ is the Plank constant and $\mathrm{E}_{\mathrm{a}}$ the DFT activation energy.

Considering the calculation of the activation energies related to migrations, while the DFT determination of barriers inside a bulk material (e.g., the migration of a vacancy in $\mathrm{Al}$ ) does not present any particular difficulty, the barrier of migration through the interface between two different materials, having lattice mismatch as large as $15 \%$ (e.g., $\mathrm{Al}$ and $\mathrm{Ni}$ ) or different crystal structures (e.g., $\mathrm{Al}$ and $\mathrm{Al} \mathrm{Ni}$ based alloys), is not trivial. However, an accurate description of these difficult reaction paths is beyond the scope of this contribution. We made two simplifying assumptions, imaged in Fig. 1, in order to approximate these barriers:

1. We consider that the transition state is located at the exact virtual frontier separating two defined layers in our model. The environment felt by the migrating species when passing through this fictitious line is the average of the composition of both layers implied in the migration.

This averaging procedure leads to approximate geometries of the transition states. More accurate geometries can

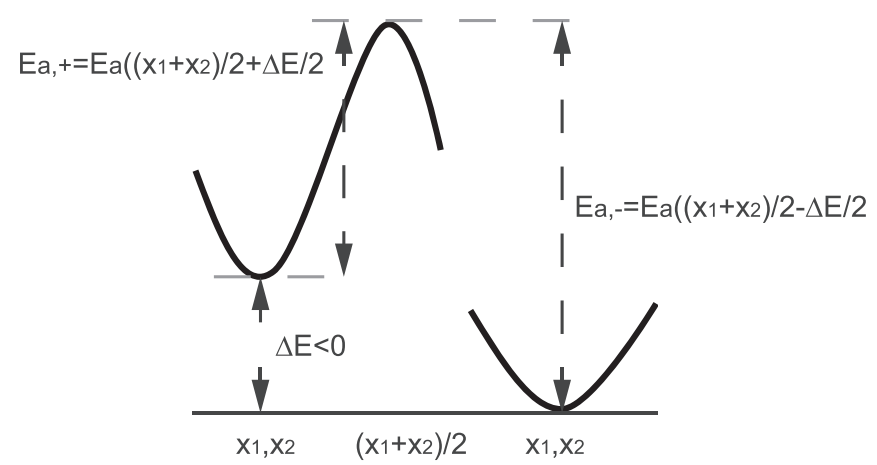

FIG. 1. Determination of the activation energy for a migration between layers 1 and 2 of different compositions ( $\mathrm{x} 1$ and $\mathrm{x} 2$ ). 
be obtained if local atomic structures are considered. But, in this situation, the chemical kinetic theory can no more be applied, and one has to switch to a kinetic Monte Carlo scheme.

Therefore, the activation energy is calculated on the basis of this particular composition. The energy as a function of the composition is established through DFT calculations by interpolation procedure between three basic structures, $\mathrm{Al}, \mathrm{Ni}$ and $\mathrm{NiAl}$, as detailed in the DFT result section here after. Along this line, specific crystalline or liquid phases are not considered when setting up our simplified energetic model.

2. The difference between the activation energies in the forward and backward directions is equal to the energy difference of the reaction. We calculate the forward activation energy by adding half the energy difference to the activation energy calculated using the averaging approximation exposed in the previous paragraph. Similarly, we calculated the backward activation energy by subtracting half the energy difference from the averaged activation energy.

This allows us to obtain the expressions given in Table I for the activation energies: $\mathrm{E}_{\mathrm{a},+}$ and $\mathrm{E}_{\mathrm{a},-}$ are, respectively, the activation energies in the forward and backward directions. $\mathrm{E}_{\mathrm{a}, \mathrm{AlV}}, \mathrm{E}_{\mathrm{a}, \mathrm{NiV}}$ and $\mathrm{E}_{\mathrm{a}, \mathrm{INiNN}}$ are, respectively, the compositiondependent activation energies of Al-V exchange, Ni-V exchange and interstitial migration.

For the Frenkel pairs creation and annihilation, DFT calculations show that their creation is only possible at high temperatures, where the ignition has already started, and their annihilation straightforward up to second nearest neighbor distances. A low activation energy barrier of $0.1 \mathrm{eV}$ has been assigned to his straightforward mechanism, for numerical purposes detailed in Sec. II D.

\section{Thermal sub-model}

The changes in composition result in energy gain that translates into a temperature rise

$$
\begin{aligned}
\Delta \mathrm{T} & =\frac{-\Delta \mathrm{E}-\mathrm{dt} \times\left(\mathrm{P}_{\mathrm{rad}}+\mathrm{P}_{\text {conv }}\right)}{3 \mathrm{k}_{\mathrm{B}} \times \sum_{\mathrm{i}}([\mathrm{L}(\mathrm{Al})]+[\mathrm{L}(\mathrm{Ni})]+[\mathrm{I}(\mathrm{Ni})])}, \\
\mathrm{P}_{\text {rad }} & =\mathrm{S} \times \varepsilon \times \sigma \times\left(\mathrm{T}^{4}-\mathrm{T}_{\mathrm{ext}}^{4}\right), \\
\mathrm{P}_{\text {conv }} & =\mathrm{S} \times \alpha \times\left(\mathrm{T}-\mathrm{T}_{\text {ext }}\right),
\end{aligned}
$$

where $\mathrm{dt}$ is the time step and $\Delta \mathrm{E}$ is the energy released during the time step. $\mathrm{S}$ is the atomic area of a single $\mathrm{Ni}$ in a (111) surface $\left(7.6 \AA^{2}\right)$. $P_{\text {rad }}$ is the power lost through radiation, $\sigma$ is the Stefan-Boltzmann constant, and $\varepsilon$ is the emissivity coefficient. We use $\varepsilon=0.2$, a value consistent with a non-polished metal. $\mathrm{P}_{\text {conv }}$ is the power lost through convection and $\alpha$ is the heat transfer coefficient $\left(5 \mathrm{~W} \mathrm{~K}^{-1} \mathrm{~m}^{-2}\right)$. The denominator is simply the heat capacity of the system.

Here, we neglect the thermal conductivity: As we are investigating thin metal films (few tens of monolayers) in which thermal transport is much faster than matter transport, we consider the thermalization as instantaneous.

\section{Numerical details}

The rate equations are integrated using the Runge$\mathrm{Kutta}^{4,5}$ method with a time step dynamically derived from the rate constants

TABLE I. Equations setting for the calculation of environment dependent activation barriers.

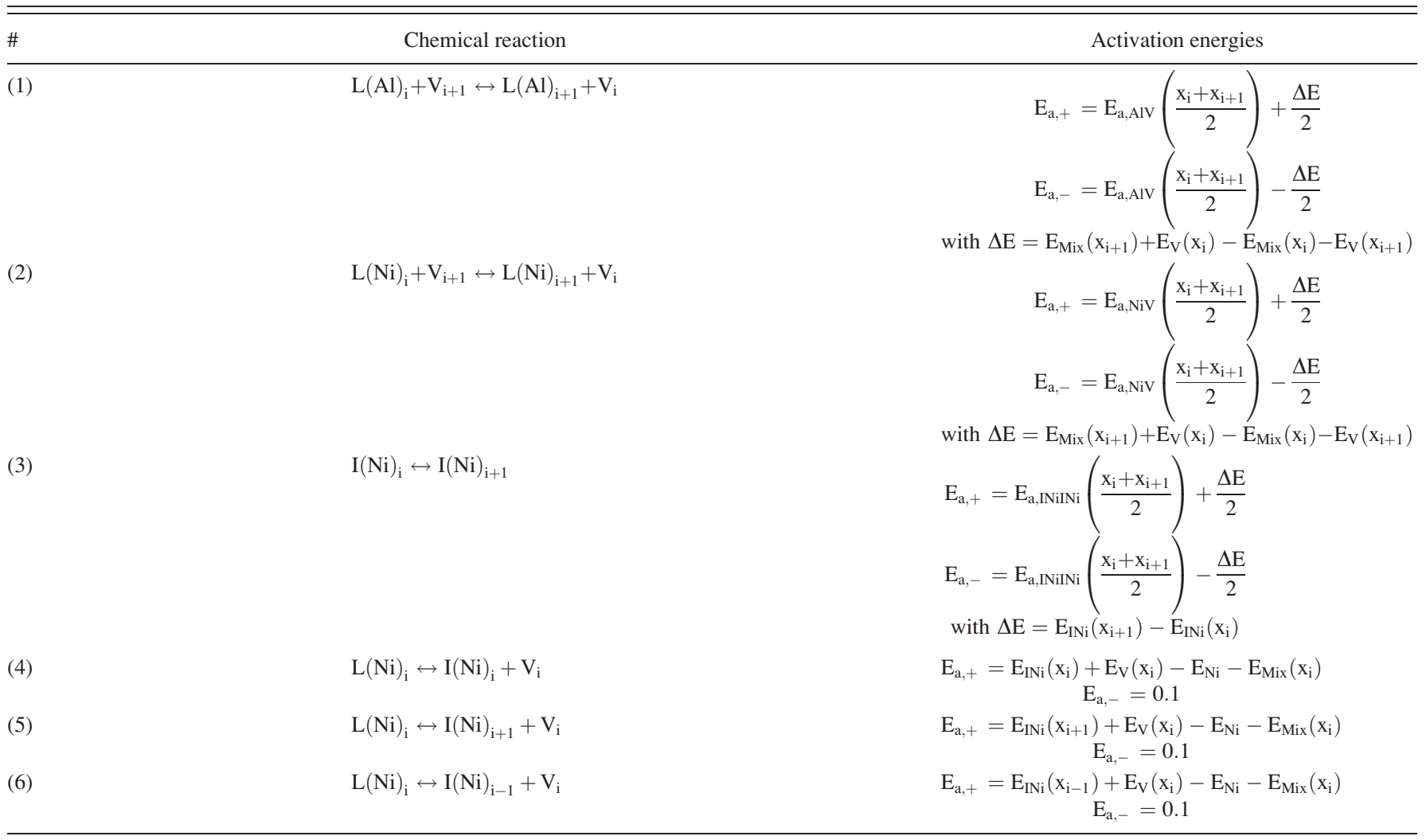




$$
\mathrm{dt}=\frac{1}{\mathrm{k}_{\max }},
$$

where $\mathrm{k}_{\max }$ is the largest rate constant. This definition allows to use larger time steps at low temperatures, when the reactions are slow, and to use smaller ones at higher temperatures when the reactions are becoming fast while enforcing matter conservation.

Moreover, in order to improve numerical stability of our model, the activation energies are not allowed to become smaller than $0.1 \mathrm{eV}$. Therefore, if activation energy becomes smaller than $0.1 \mathrm{eV}$, it is reset to $0.1 \mathrm{eV}$ and the activation energy of the reverse reaction set to $0.1 \pm \Delta \mathrm{E}$ in order to keep the difference between the activation energies equal to $\Delta \mathrm{E}$. This value has been used for Frenkel pair recombination. $0.1 \mathrm{eV}$ is an arbitrary value that appears to be a good compromise between suitable time step and occurrence of the mechanism even at room temperature. This means that it makes the reaction sufficiently fast to precede all other mechanisms, and sufficiently slow to preserve relevant time steps.

Finally, the model proceeds according to the flowchart of Fig. 2.

\section{DFT CALCULATIONS}

\section{A. Computational details}

All the DFT calculations have been performed with the VASP 5.2 code $^{33-36}$ using the local density approximation, ${ }^{37}$ which is appropriate for metals. The valence electrons were described by a plane wave basis set with a kinetic energy cutoff of $300 \mathrm{eV}$ while the ion cores were represented using the projector augmented wave method. ${ }^{38,39}$ The Brillouin zone sampling was performed on a $3 \times 3 \times 3$ MonkhorstPack mesh. Electronic occupancies were determined according to a first order Methfessel-Paxton scheme with an energy

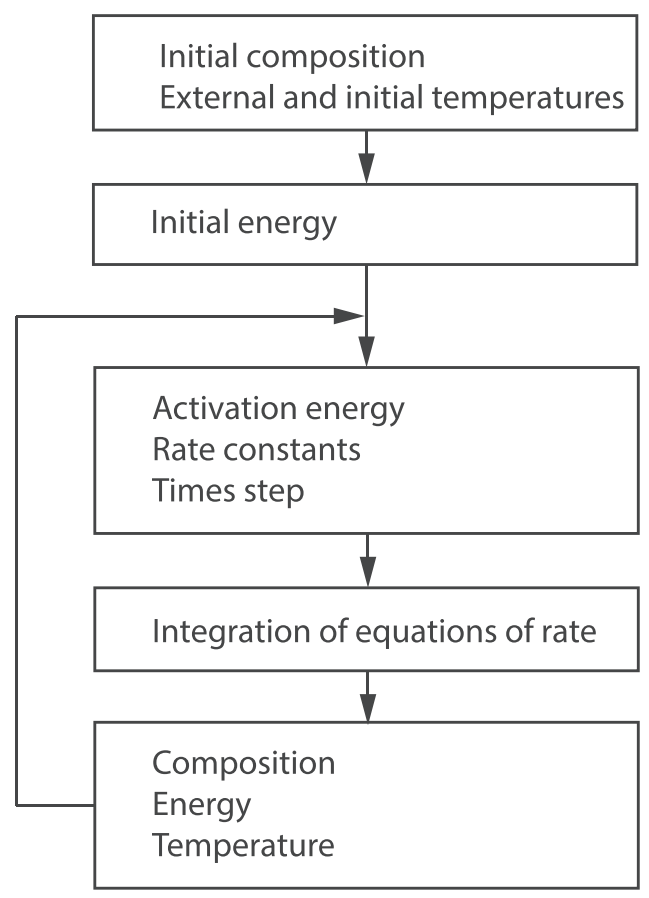

FIG. 2. Flowchart of the computing sequence. smearing of $0.2 \mathrm{eV}$. Calculations in nickel were performed within the local spin density approximation to account for its ferromagnetic character.

Cubic supercells built from 27 face centered cubic cells, containing a total of 108 atoms, are representing aluminum and nickel bulks and a cubic supercell built from 64 body centered cubic cells, containing 128 atoms, is representing bulk AlNi alloy. After optimizing the volume of the three supercells, we obtain the following lattice parameters $\mathrm{a}_{\mathrm{Al}}=3.99 \AA, \mathrm{a}_{\mathrm{Ni}}=3.43 \AA$, and $\mathrm{a}_{\mathrm{AlNi}}=2.83 \AA$ in good agreement with experimental ones.

\section{B. DFT study to parametrize the macroscopic model}

In all following DFT calculations, formation energies and activation barriers are systematically determined for three compositions: bulk $\mathrm{Al}(\mathrm{x}=0)$, bulk $\mathrm{Ni}(\mathrm{x}=1)$, and AlNi $(x=0.5)$. To obtain the composition-dependence of the energies, we perform a second order polynomial interpolation, using the three calculated values for each investigated atomic scale mechanisms. Energies per atom, activation energies, and energy functions are summarized in Table II.

\section{1. $E_{A /}$ and $E_{N i}$}

The $\mathrm{E}_{\mathrm{A} 1}$ and $\mathrm{E}_{\mathrm{Ni}}$ parameters represent the respective energies of an $\mathrm{Al}$ atom in an $\mathrm{Al}$ bulk and of a $\mathrm{Ni}$ atom in a Ni bulk, both set in lattice positions. They are defined as the per-atom energy of the $\mathrm{Al}$ and $\mathrm{Ni}$ supercells, respectively. We obtain $\mathrm{E}_{\mathrm{Al}}=-4.186 \mathrm{eV}$ and $\mathrm{E}_{\mathrm{Ni}}=-6.578 \mathrm{eV}$.

\section{2. $E_{\text {Mix }}$}

$\mathrm{E}_{\mathrm{Mix}}$ is the mixing energy, i.e., the per-atom energy excess of a mixture with respect to pure $\mathrm{Al}$ or $\mathrm{Ni}$. This term is made composition-dependent using the following method:

- In pure metals: $\mathrm{Al}$ and $\mathrm{Ni}$, we set $\mathrm{E}_{\mathrm{Mix}}=0$.

- In $\mathrm{AlNi}, \mathrm{E}_{\mathrm{Mix}}=-0.716 \mathrm{eV}$ is the per-atom excess energy with respect to the two pure $\mathrm{Al}$ and Ni bulks, which is also the energy of the reaction

$$
\frac{1}{2} \mathrm{Al}+\frac{1}{2} \mathrm{Ni} \leftrightarrow \frac{1}{2} \mathrm{AlNi} .
$$

- We finally perform the polynomial interpolation of $\mathrm{E}_{\mathrm{Mix}}$ (see Table II) and obtain the following expression plotted on Fig. 3:

$$
\mathrm{E}_{\text {Mix }}(\mathrm{x})=2.865 \mathrm{x}^{2}-2.865 \mathrm{x} .
$$

\section{3. $E_{I N i}$}

$\mathrm{E}_{\mathrm{INi}}$ is the energy of a nickel atom in interstitial position. It is straightforwardly defined as the difference between the energy of a supercell containing an interstitial and the energy of the supercell without the interstitial. We obtain $\mathrm{E}_{\mathrm{INi}}(0)$ $=-6.709 \mathrm{eV}, \mathrm{E}_{\mathrm{INi}}(0.5)=-2.982 \mathrm{eV}$, and $\mathrm{E}_{\mathrm{INi}}(1)=-1.508 \mathrm{eV}$ (see Table II).

Obviously, when $\mathrm{E}_{\mathrm{INi}}$ is smaller than $\mathrm{E}_{\mathrm{Ni}}$, this indicates that the nickel atom is more stable in interstitial position 
TABLE II. Calculated energies per atom and activation energies given as a function of the composition $(\mathrm{x}=0,0.5,1)$. All energies are in eV. Reduced bulks illustrate considered atomic scale mechanisms where green and blue spheres represent aluminum and nickel atoms, respectively. Second order polynomial equations are provided.

\begin{tabular}{|c|c|c|c|c|}
\hline Energy (eV) & $\mathrm{Al}$ system & AlNi system & Ni system & Polynomial equation \\
\hline $\mathrm{E}_{\mathrm{Al}}$ & -4.186 & l & l & l \\
\hline $\mathrm{E}_{\mathrm{Ni}}$ & / & / & -6.578 & l \\
\hline Mixing energy $\left(\mathrm{E}_{\mathrm{Mix}}\right)$ & & & & $\mathrm{E}_{\mathrm{Mix}}(\mathrm{x})=2.865 \mathrm{x}^{2}-2.865 \mathrm{x}$ \\
\hline $\mathrm{Ni}$ interstitial $\left(\mathrm{E}_{\mathrm{INi}}\right)$ & & & & $\mathrm{E}_{\mathrm{INi}}(\mathrm{x})=-4.506 \mathrm{x}^{2}+9.706 \mathrm{x}-6.709$ \\
\hline Energy of a vacancy $\left(E_{V}\right)$ & & & & $\mathrm{E}_{\mathrm{v}}(\mathrm{x})=-0.1216 \mathrm{x}^{2}+1.131 \mathrm{x}+0.6457$ \\
\hline
\end{tabular}

Activation energy of the Al-vacancy exchange $\left(\mathrm{E}_{\mathrm{a}, \mathrm{AlV}}\right)$

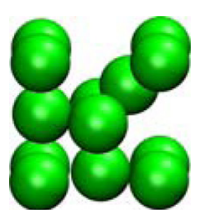

0.635

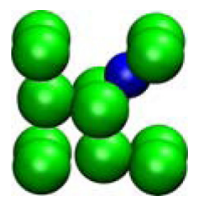

0.990

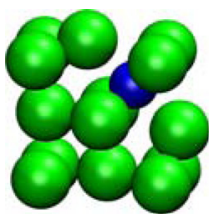

1.024

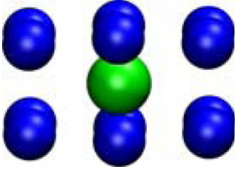

1.301

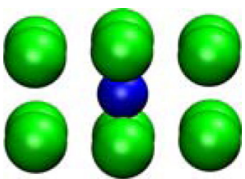

2.719

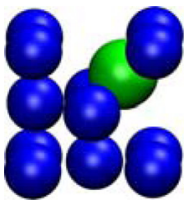

0.747

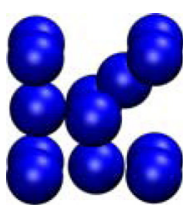

1.239

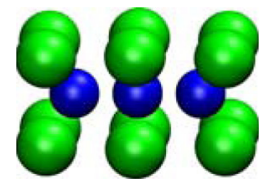

0.476

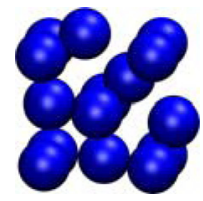

0.813
$E_{a, A l V}(x)=-2.483 x^{2}+2.573 x+0.6347$

$\mathrm{E}_{\mathrm{a}, \mathrm{NiV}}(\mathrm{x})=-6.550 \mathrm{x}^{2}+6.863 \mathrm{x}+0.9261$

$\mathrm{E}_{\mathrm{a}, \mathrm{INiNN}}(\mathrm{x})=1.771 \mathrm{x}^{2}-1.982 \mathrm{x}+1.024$
Activation energy of the Ni interstitial migration $\left(\mathrm{E}_{\mathrm{a}, \mathrm{IN} \text { IN }}\right)$

$$
\mathrm{E}_{\mathrm{V}}=\mathrm{E}_{\mathrm{vacancy}}-\frac{\mathrm{n}-1}{\mathrm{n}} \mathrm{E}_{\text {bulk }}
$$

where $E_{\text {vacancy }}$ is the energy of the supercell with a vacancy, $\mathrm{E}_{\text {bulk }}$ is the energy of the supercell without the vacancy, and $\mathrm{n}$ is the number of atoms in the bulk cell. 


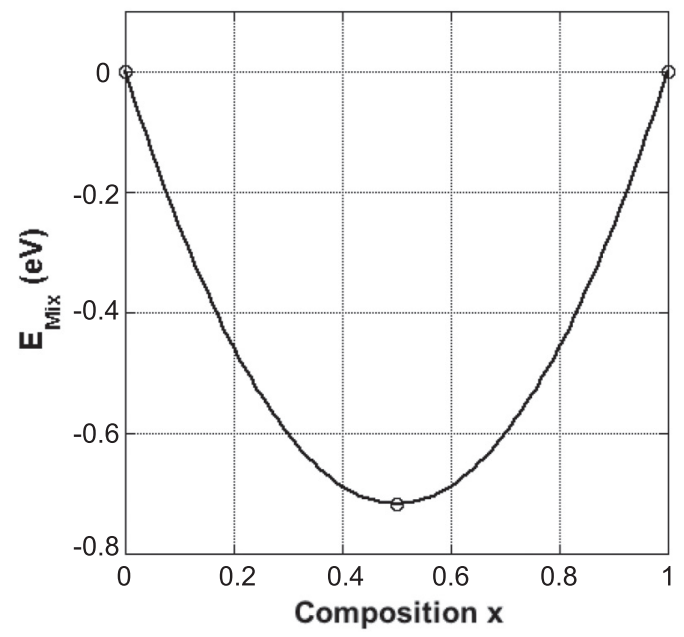

FIG. 3. The mixing energy $\left(\mathrm{E}_{\mathrm{Mix}}\right)$ as a function of the composition ( $\mathrm{x}$ ) through a polynomial interpolation arose from DFT data and used in the present study.

For the sake of simplicity, we only consider the existence of isolated vacancies and neglect their clustering into voids.

Calculations in bulk $\mathrm{Al}$ and bulk $\mathrm{Ni}$ yield $\mathrm{E}_{\mathrm{V}}(0)$ $=0.655 \mathrm{eV}$ and $\mathrm{E}_{\mathrm{V}}(1)=1.664 \mathrm{eV}$, respectively.

Obviously, the aforementioned formula is not valid for mixtures. Moreover, we do not want to make any difference between vacancies formed by the departure of an $\mathrm{Al}$ or a $\mathrm{Ni}$ atom, while their formation energies are different. To solve this issue, we opted for averaging the formation energies of both kinds of vacancies in AlNi using this modified formula

$$
\mathrm{E}_{\mathrm{V}}=\frac{\mathrm{E}_{\text {Alvacancy }}+\mathrm{E}_{\text {Nivacancy }}}{2}-\frac{\mathrm{n}-1}{\mathrm{n}} \mathrm{E}_{\text {bulk }}
$$

where $\mathrm{E}_{\mathrm{Al} \text { vacancy }}$ and $\mathrm{E}_{\mathrm{Nivacancy}}$ are the vacancy formation energies in bulk aluminum and bulk Nickel, respectively. We obtain $\mathrm{E}_{\mathrm{V}}(0.5)=1.190 \mathrm{eV}$ (see Table II) leading to the following polynomial equation:

$$
\mathrm{E}_{\mathrm{v}}(\mathrm{x})=-0.1216 \mathrm{x}^{2}+1.131 \mathrm{x}+0.6457 .
$$

\section{5. $E_{a, A I V}$ and $E_{a, N i V}$}

Vacancies migrate through exchanges with lattice atoms. $\mathrm{E}_{\mathrm{a}, \mathrm{AlV}}$ and $\mathrm{E}_{\mathrm{a}, \mathrm{NiV}}$ are the activation energies corresponding the exchange with an $\mathrm{Al}$ and a Ni lattice atom, respectively.

We determine $\mathrm{E}_{\mathrm{a}, \mathrm{Alv}}$ by calculating the three activation energies of the exchange of an $\mathrm{Al}$ lattice atom with a vacancy in bulk Al containing a vacancy, in AlNi containing an Alvacancy and in the bulk Ni containing a vacancy and an $\mathrm{Al}$ atom close to each other. We obtain $\mathrm{E}_{\mathrm{a}, \mathrm{AlV}}(0)=0.635 \mathrm{eV}$, $\mathrm{E}_{\mathrm{a}, \mathrm{AlV}}(0.504)=1.301 \mathrm{eV}$, and $\mathrm{E}_{\mathrm{a}, \mathrm{AlV}}(0.991)=0.747 \mathrm{eV}$.

Similarly, we determine $\mathrm{E}_{\mathrm{a}, \mathrm{NiV}}$ by calculating the three activation energies of the exchange of a Ni lattice atom with a vacancy in bulk $\mathrm{Al}$ containing a vacancy and a $\mathrm{Ni}$ atom close to each other, in AlNi containing an Ni-vacancy and in the bulk $\mathrm{Ni}$ containing a vacancy. We obtain
$\mathrm{E}_{\mathrm{a}, \mathrm{NiV}}(0.09)=0.990 \mathrm{eV}, \quad \mathrm{E}_{\mathrm{a}, \mathrm{NiV}}(0.496)=2.719 \mathrm{eV}, \quad$ and $\mathrm{E}_{\mathrm{a}, \mathrm{NiV}}(1)=1.239 \mathrm{eV}$ (see Table II).

We can notice that $\mathrm{E}_{\mathrm{a}, \mathrm{NiV}}$ is always larger than $\mathrm{E}_{\mathrm{a}, \mathrm{AlV}}$ which shows that $\mathrm{Al}$ lattice atoms are more mobile than $\mathrm{Ni}$ lattice atoms.

\section{6. $E_{a, I N i I N i}$}

$\mathrm{E}_{\mathrm{a}, \mathrm{INiNi}}$ is the activation energy of an interstitial nickel atom migrating from a layer to an adjacent one. By performing DFT calculations in $\mathrm{Al}, \mathrm{Ni}$ and $\mathrm{AlNi}$, we obtain $\mathrm{E}_{\mathrm{a}, \mathrm{INiINi}}(0)=1.024 \mathrm{eV}, \quad \mathrm{E}_{\mathrm{a}, \mathrm{INiINi}}(1)=0.813 \mathrm{eV}$ and $\mathrm{E}_{\mathrm{a}, \mathrm{INiINi}}(0.5)=0.476 \mathrm{eV}$ (see Table II).

\section{RATE EQUATION RESULTS}

The set of rate equations described in Sec. III has been applied to the ignition of $\mathrm{Al} / \mathrm{Ni}$ multilayers, using activation energies and rate constants defined in Sections II and III. At first, we investigate the effect of the external temperature. These simulations are started with a small density of vacancies to hinder the effect of defects on the ignition process. In a second part, we examine the influence of the slab composition, i.e., the varying amount of vacancies, which can originate from different deposition conditions. The $\mathrm{Al} / \mathrm{Ni}$ lattices mismatch of $15 \%$ would lead to empirically $30 \%$ of vacancies to be introduced in our model interface. However, in real systems, we can expect a lower level of vacancies due to the strain and associated relaxation in both materials. We finally consider the effect of the system pre-exposure to temperature, i.e., ignition properties on pre-mixed layers.

\section{A. Influence of the temperature}

In this part, the starting system is composed of 25 layers of aluminum and 25 layers of nickel, all the 50 layers containing $1 \%$ vacancies. A numbering from 1 to 50 is used hereafter, referring to the 50 layers stacking, where layers from 1 to 25 correspond initially to the 25 aluminum layers and layers from 26 to 50 correspond initially to the 25 nickel layers; layers 25 and 26 are the interfacial layers, initially composed of $\mathrm{Al}$ and $\mathrm{Ni}$ species, respectively. Simulations are run at $300^{\circ} \mathrm{C}, 500^{\circ} \mathrm{C}, 700^{\circ} \mathrm{C}, 800^{\circ} \mathrm{C}, 900^{\circ} \mathrm{C}$, and $1000^{\circ} \mathrm{C}$ external temperatures. The resulting thermograms describing the temperature increase upon applied stimulus are displayed in Fig. 4.

As could be expected, external temperature plays a major role on the ignition process. The general trend is an increase of the slab temperature, due to interlayer migration and reaction, followed by its decrease down to the external temperature, resulting from radiative and convective heat exchanges with the ambient. We have calculated the adiabatic temperature increase, in the absence of all heat transfer to the ambient, to be $2771^{\circ} \mathrm{C}$.

The simulations run at $300^{\circ} \mathrm{C}$ and $500{ }^{\circ} \mathrm{C}$ show no significant temperature increase: The maximum temperature increases are $19{ }^{\circ} \mathrm{C}$ and $94^{\circ} \mathrm{C}$, respectively. These low temperature increases are accompanied by low intermixing as can be seen in Table III: Only layer 26, which is the Ni layer in close contact with the aluminum layers, exhibits a mixed 


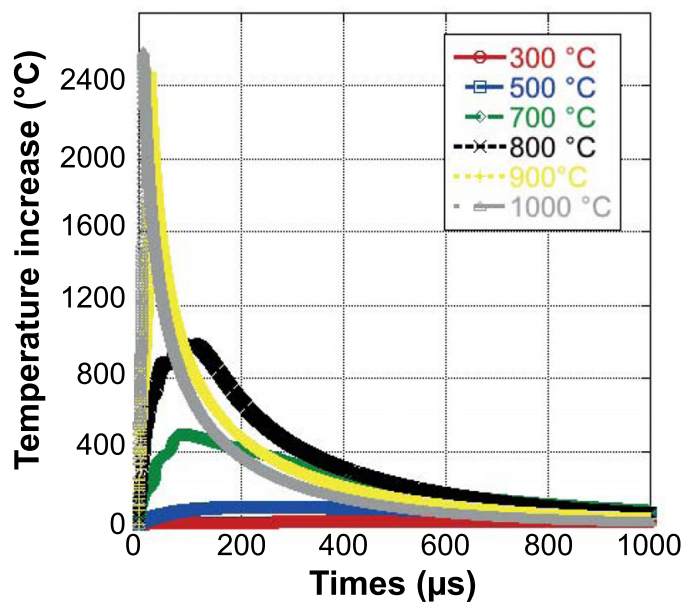

FIG. 4. Temperature increase as a function of time for different external temperatures.

composition while the 49 others (both $\mathrm{Al}$ and $\mathrm{Ni}$ ) are almost pure $\mathrm{Al}$ or $\mathrm{Ni}$. We also notice that the vacancies migrate from $\mathrm{Ni}$ to $\mathrm{Al}$, as could be expected from their stability in $\mathrm{Al}$ and $\mathrm{Ni}$ (Table II), which points the $\mathrm{Al}$ ability to "dissolve" nickel.

The simulations run at $700^{\circ} \mathrm{C}$ and $800^{\circ} \mathrm{C}$ show significantly larger temperature increases: $492^{\circ} \mathrm{C}$ and $986^{\circ} \mathrm{C}$. These temperature increases allow reaching maximum temperatures of $1192^{\circ} \mathrm{C}$ and $1786^{\circ} \mathrm{C}$, respectively. These temperature increases are substantial but very far from $2771^{\circ} \mathrm{C}$, the adiabatic maximum temperature increase within our model. The result is a significantly larger mixing than in the previous cases, but the reaction is still far from completion since a full mixing is not observed, as shown in Fig. 5, illustrating the layers compositions throughout the layers stacking. However, these massive mixing profiles before ignition can be compared with early mixings reported in literature where intermediate AlNi alloys have been elucidated. ${ }^{19,40-42}$

These final compositions shed light on the mainstream atomic mixing mechanisms: Indeed, Ni appears to "dissolve" into $\mathrm{Al}$ in agreement with published MD simulation. ${ }^{21,40}$ The concentration of $\mathrm{Ni}$ in the Al-rich phase is significantly larger than that of $\mathrm{Al}$ in the Ni-rich phase. Thus, matter conservation requires a displacement of the interface between $\mathrm{Ni}$ and $\mathrm{Al}$ phases toward the $\mathrm{Ni}$ domain such that the number of Al-rich layers increases as the mixing proceeds. This behavior, which may seem counter-intuitive, has already been observed in fully atomistic simulations and therefore cannot be an artifact of our model. It is to be emphazised that not only $\mathrm{Ni}$ "dissolves" into $\mathrm{Al}$ but also vacancies do massively migrate towards bulk Al.

The simulations run at $900{ }^{\circ} \mathrm{C}$ and $1000^{\circ} \mathrm{C}$ exhibit a different behavior. First, the respective temperature increases,

TABLE III. Initial and final compositions of the system ignited at $500^{\circ} \mathrm{C}$.

\begin{tabular}{lccccccc}
\hline \hline & \multicolumn{3}{c}{ Initial } & & \multicolumn{3}{c}{ Final (1 ms) } \\
\cline { 2 - 4 } \cline { 6 - 8 } & $\mathrm{Al}$ & $\mathrm{Ni}$ & $\mathrm{V}$ & & $\mathrm{Al}$ & $\mathrm{Ni}$ & $\mathrm{V}$ \\
\hline Layer 1-25 & 0.99 & 0 & 0.01 & & 0.97 & 0.01 & 0.02 \\
Layer 26 & 0 & 0.99 & 0.01 & & 0.17 & 0.83 & 0 \\
Layer 27-50 & 0 & 0.99 & 0.01 & & 0.01 & 0.99 & 0 \\
\hline \hline
\end{tabular}

$2471^{\circ} \mathrm{C}$ and $2590{ }^{\circ} \mathrm{C}$, are significantly larger than the previous ones and closer to the adiabatic value $\left(2771^{\circ} \mathrm{C}\right)$. We can also observe that, as expected, a higher external temperature leads to a faster ignition as the maximum temperature is reached after $21 \mu \mathrm{s}$ at $900^{\circ} \mathrm{C}$ and $9 \mu$ s at $1000^{\circ} \mathrm{C}$. Moreover, the temperature profiles show completely different shapes from those observed at lower external temperatures: The temperature increase is very steep at the beginning and the temperature decay is faster. This behavior can be ascribed to the complete or nearly complete reactions. Indeed, all the layers have the same composition after $28 \mu$ s at $900^{\circ} \mathrm{C}$ and $11 \mu \mathrm{s}$ at $1000^{\circ} \mathrm{C}$, leaving no reactant behind to slow down the cooling. These ignition temperatures are slightly lower than experimental findings (over $1100^{\circ} \mathrm{C}$ ) but still in good agreement if we consider the $a b$ initio nature of our mechanisms, the low dimensionality of our system, and its intrinsic limitations: The second order polynomial interpolation may not be enough accurate and higher order fit may be required, which would require DFT calculations on more intermediate compositions, the potential interface strain due to lattice mismatch which is not considered and could alter the activation energies, and finally, the lack of knowledge of vacancy concentration and spatial distribution.

\section{B. Influence of the vacancies}

Here, we use the same slab composed of 25 layers $\mathrm{Al}$ and 25 layers of $\mathrm{Ni}$ but with different amounts of initial vacancy concentration. Here, the vacancies species are homogeneously shared throughout the stacking layers. Assuming a homogeneous vacancy distribution results from the essence of the chemical kinetic theory, where specific local structures are not taken into account. The introduction of any type of inhomogeneity should therefore be made on an arbitrary basis, although inhomogeneities are certainly present in real experiments. Along the same line, where vacancies are only present in one of the materials ( $\mathrm{Al}$ or $\mathrm{Ni}$ ), simulations show that, as a result of vacancy migrations, they are very rapidly distributed uniformly in the Al layers.

Five cases have been examined: no vacancy, $10^{-4}$ in $\mathrm{Ni}$ and $10^{-4}$ in $\mathrm{Al}, 10^{-3}$ in $\mathrm{Ni}$ and $10^{-3}$ in $\mathrm{Al}, 10^{-2}$ in $\mathrm{Ni}$ and $10^{-2}$ in $\mathrm{Al}, 10^{-1}$ in $\mathrm{Ni}$ and $10^{-1}$ in $\mathrm{Al}$, while setting the external temperature at $800^{\circ} \mathrm{C}$ for all the simulations. The simulated thermograms are displayed in Fig. 6.

We observe that at lower vacancy concentrations: $\mathrm{V}=0, \mathrm{~V}=10^{-4}$ and $\mathrm{V}=10^{-3}$, simulations lead to almost identical results, with a maximum temperature slightly above $1300^{\circ} \mathrm{C}$. This behavior is an indication of a weak atomic mixing. At $\mathrm{V}=10^{-2}$, the maximum temperature is significantly higher, close to $1800{ }^{\circ} \mathrm{C}$, which indicates a larger but still incomplete mixing. Finally, the simulation with $\mathrm{V}=10^{-1}$ exhibits a very different behavior, with a very steep temperature increase, up to a temperature above $3500{ }^{\circ} \mathrm{C}$, and a fast cool down. As seen in Sec. IV A, this is the signature of a total mixing.

Therefore, we observe that increasing the amount of vacancies leads to a faster ignition and more complete reactions, which is not surprising as vacancies are involved in the mixing reactions at low temperatures as can be seen from 

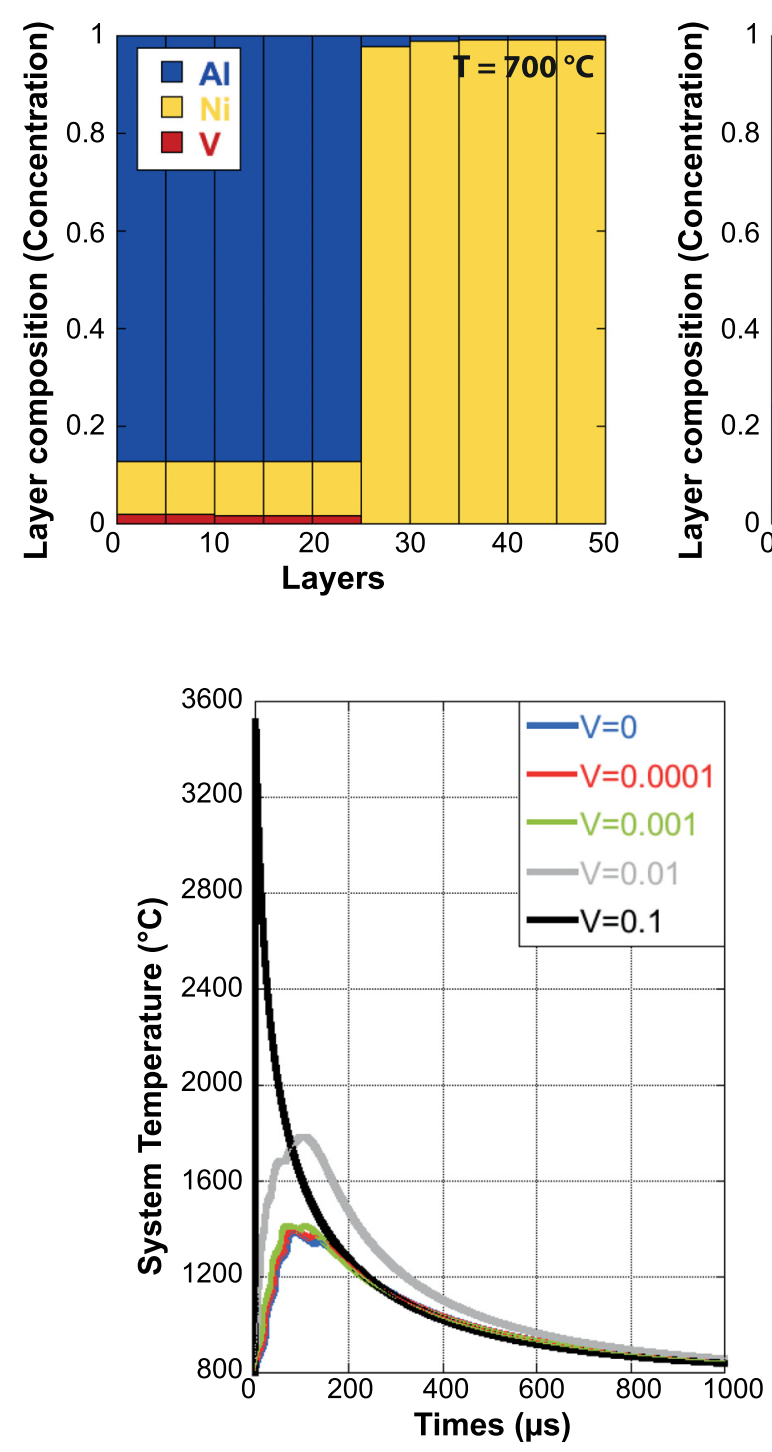

FIG. 6. System temperature as a function of time for different starting amounts of vacancies using an external applied temperature of $800^{\circ} \mathrm{C}$.

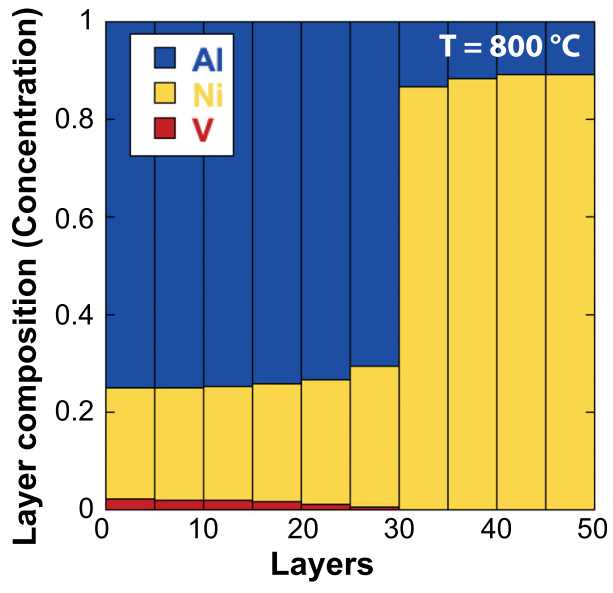

FIG. 5. Composition as a species concentration for the simulations run at $700^{\circ} \mathrm{C}$ (left) and $800^{\circ} \mathrm{C}$ (right) after $1 \mathrm{~ms}$. Blue, yellow and red zones correspond to $\mathrm{Al}$, $\mathrm{Ni}$ and $\mathrm{V}$ species concentrations.

written reaction mechanisms and in literature. ${ }^{27,43}$ The alternative mechanism for inducing atomic migration would be the Frenkel pair creation. However this necessitates, in the best conditions, right at the interface, around $1.6 \mathrm{eV}$ activation, making this event only probable at higher temperatures (over $500{ }^{\circ} \mathrm{C}$ ). We can conclude that the presence of vacancies in the deposited films can efficiently counterbalance the effect of higher external temperatures for the ignition of $\mathrm{Al} /$ Ni slabs. ${ }^{43}$

In order to gain more insights into the role of the initial localization of the vacancies, we have performed two additional sets of simulations. Using the same systems, we introduce the vacancies in only one metal homogeneously shared throughout the considered metal, either $\mathrm{Al}$ or $\mathrm{Ni}$. The two sets of simulations are therefore run at an external temperature of $800^{\circ} \mathrm{C}$, with the following amounts of initial vacancies:

No vacancy in $\mathrm{Al}, 10^{-4}$ in $\mathrm{Ni} \quad$ No vacancy in $\mathrm{Ni}, 10^{-4}$ in $\mathrm{Al}$

No vacancy in $\mathrm{Al}, 10^{-3}$ in $\mathrm{Ni}$

No vacancy in $\mathrm{Ni}, 10^{-3}$ in $\mathrm{Al}$

No vacancy in $\mathrm{Al}, 10^{-2}$ in $\mathrm{Ni}$

No vacancy in $\mathrm{Ni}, 10^{-2}$ in $\mathrm{Al}$

No vacancy in $\mathrm{Al}, 10^{-1}$ in $\mathrm{Ni}$

No vacancy in $\mathrm{Ni}, 10^{-1}$ in $\mathrm{Al}$

The corresponding thermograms are displayed in Fig. 7.
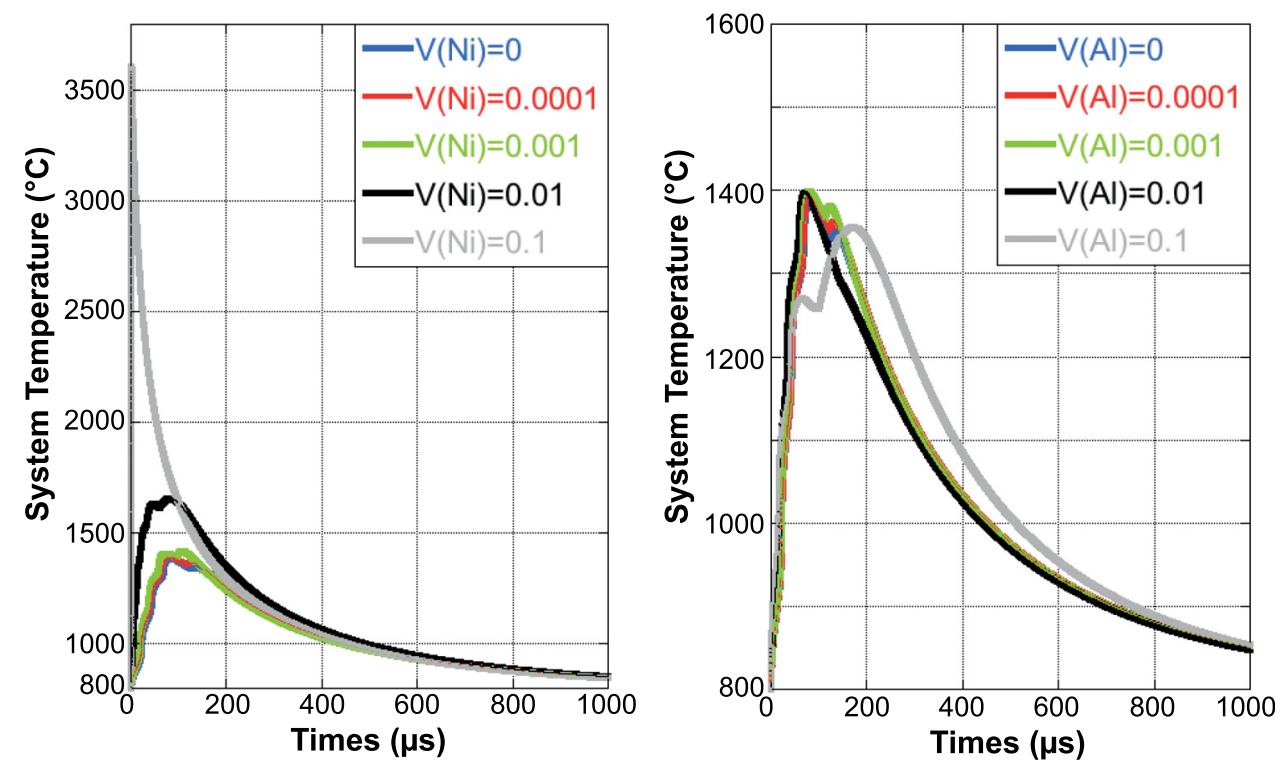

FIG. 7. System temperature as a function of time for varying initial amounts of vacancies in $\mathrm{Ni}$ (left) and $\mathrm{Al}$ (right) and none in the other metal, respectively, using an external applied temperature of $800^{\circ} \mathrm{C}$. 
Comparing both curves, it is obvious that vacancies in $\mathrm{Ni}$ have a dramatic influence on the ignition properties, while vacancies in $\mathrm{Al}$ only play a marginal role. Indeed, with no vacancy in Al layers, we almost recover the curves displayed in Fig. 6, where equivalent amounts of vacancies were also present in Al layers. On the other hand, with no vacancy in Ni layers, all thermograms are almost identical, whatever the amount of vacancies introduced in Al layers. The only observed effect is a slight slow down of the reaction, for vacancy concentrations in $\mathrm{Al}$ as large as $10 \%$. Based on the results displayed in Table II, vacancies are significantly more stable in $\mathrm{Al}$ than in Ni. Therefore, their diffusion from $\mathrm{Ni}$ to $\mathrm{Al}$ is much easier than from $\mathrm{Al}$ to $\mathrm{Ni}$. When all the vacancies are initially in $\mathrm{Al}$, they tend to stay in $\mathrm{Al}$ and so they contribute much less to the ignition process than if they were in $\mathrm{Ni}$ as they are necessary to drain $\mathrm{Ni}$ atoms from the nickel reach regions to the $\mathrm{Al}$ domain.

\section{Influence of barrier layers}

Finally, we study the influence of a pre-annealing on the slab ignition. As starting points, we use the compositions obtained after heating during $1 \mathrm{~ms}$ the 50-layers slab with $1 \%$ vacancies at 300,500 , and $700^{\circ} \mathrm{C}$. These systems are then heated at $1000^{\circ} \mathrm{C}$, as we have previously seen it is sufficient for ignition. The temperature as a function of time is shown in Fig. 8.

As we can observe, pre-heating the system at temperatures below $500{ }^{\circ} \mathrm{C}$ (blue and red curves, respectively, 300 and $500^{\circ} \mathrm{C}$ on Fig. 8) results in small ignition delays and maximum temperature increases slightly lower than maximum temperatures without annealing. Actually, during low pre-heating, almost no mixing reaction occurs as can be observed on Fig. 9. We mention here that $9 \mu$ s is required to reach $3590^{\circ} \mathrm{C}$, that is the maximum temperature obtained without any annealing. After $1 \mathrm{~ms}$ at $300^{\circ} \mathrm{C}$, the maximum temperature, $3545^{\circ} \mathrm{C}\left(\sim 50^{\circ} \mathrm{C}\right.$ lower than the maximum temperature), is reached after $11 \mu$ s delay (decomposed in $9 \mu \mathrm{s}$ $+2 \mu \mathrm{s})$. After $1 \mathrm{~ms}$ at $500^{\circ} \mathrm{C}$, the maximum temperature, $3286{ }^{\circ} \mathrm{C}\left(\sim 300^{\circ} \mathrm{C}\right.$ lower), is reached after $28 \mu$ s with $19 \mu \mathrm{s}$ delay.

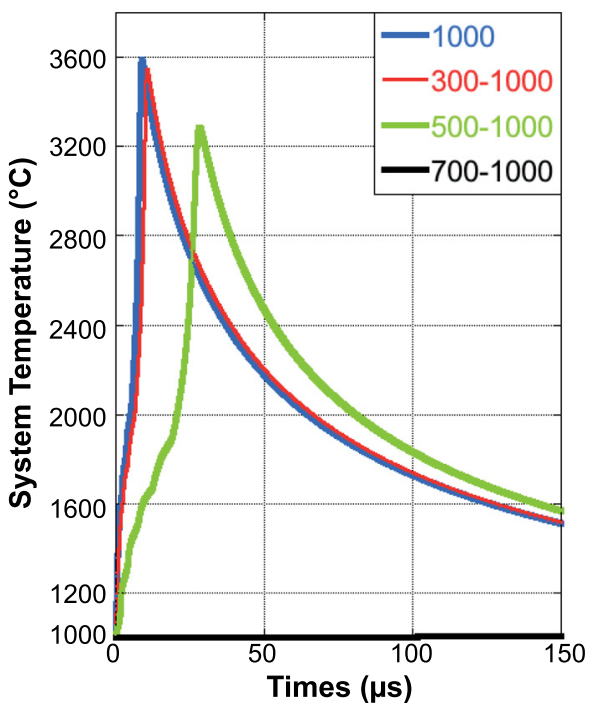

FIG. 8. System temperature as a function of time for different annealing temperatures. Blue curve represents foils heated at $1000^{\circ} \mathrm{C}$. Red, green and black curves are obtained for systems pre-annealed at 300,500 and $700{ }^{\circ} \mathrm{C}$ during $1 \mathrm{~ms}$, respectively, then heated at $1000^{\circ} \mathrm{C}$.

Here, the ignition time can be decomposed in two steps: The first delay corresponds to the species diffusion throughout the intermixing layer produced by the pre-heating process and the second arises from exothermic reactions at the interfaces.

Intermixing at the interface decreases the velocity of the ignition ${ }^{19}$ for all premixings: larger the pre-heating, thicker the premixing layer, longer the ignition and smaller the temperature are.

On the other hand, pre-heating at $700^{\circ} \mathrm{C}$, a temperature leading to a small but non-negligible mixing (see Fig. 9), is enough for deactivating the material at least with respect to $1000^{\circ} \mathrm{C}$ initiation temperature. Indeed, the maximum temperature is only $1007^{\circ} \mathrm{C}$ and is reached after $500 \mu$ s (not shown on Fig. 8). This is an illustration of the mechanisms potentially responsible for degradation of the materials due to the low activation of mass transport in the presence of vacancies.
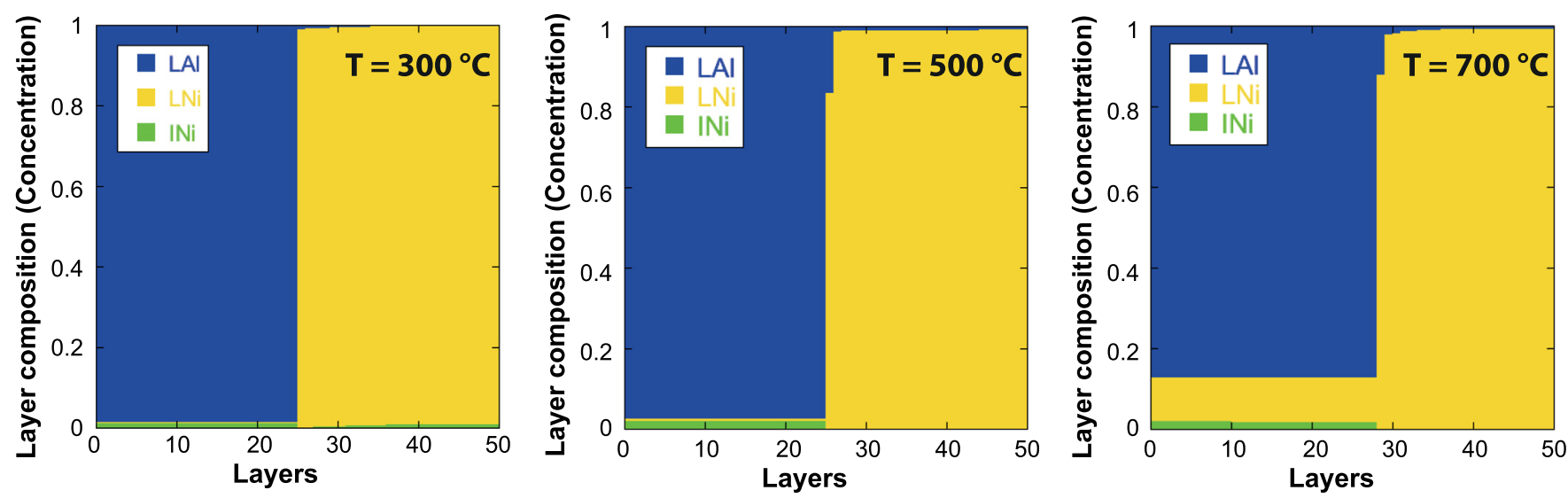

FIG. 9. Starting system layers composition as a species concentration for the pre-annealing simulations run after $1 \mathrm{~ms}$ at $300{ }^{\circ} \mathrm{C}$ (left), $500{ }^{\circ} \mathrm{C}$ (middle), and $700^{\circ} \mathrm{C}$ (right). Blue, yellow and green zones correspond to lattice $\mathrm{Al}$ atoms, lattice Ni atoms and interstitial Nickel species concentrations. 


\section{CONCLUSION}

In this contribution, we propose a bottom-up physicochemical-based modeling strategy that allows the prediction of $\mathrm{Al} / \mathrm{Ni}$ multilayer ignition properties as a function of its detailed microscopic composition, bulk layers, and interfacial regions. Using DFT calculations, we have identified elementary mechanisms related to basic atomistic events: Frenkel pair generation, $\mathrm{Al}, \mathrm{Ni}$ and vacancy migrations. On the basis of the associated calculated activation barriers, we have developed and parametrized a system of rate equations coupled with a thermal model that allows describing the kinetics and energetics of the $\mathrm{Al} / \mathrm{Ni}$ multilayers evolution as a function of an applied external temperature. This model represents properly the influence of temperature on the ignition of the material, when considering explicitly the presence of vacancies: The ignition temperature of $800^{\circ} \mathrm{C}$ with $10 \%$ vacancies is in reasonable agreement with the ignition temperature found experimentally. We show that the intermixing profile is asymmetric on either side of the initial $\mathrm{Al} / \mathrm{Ni}$ interface. We demonstrate that the mass transport is governed by two different processes where vacancies play a dominant role. At low temperatures (over room temperature) vacancies promote mostly $\mathrm{Ni}$ diffusion into $\mathrm{Al}$, thus modifying the overall nanolaminate composition profile and decreasing the available energy reservoir. This is the cause of materials degradation that is directly pointing to the experimental processing conditions for materials deposition and their ability to provide interfaces with low level of vacancies. At higher temperature, vacancies may be directly created through Frenkel pairs. This process should be concomitant (or over) to the Al fusion temperature which also can be seen, by nature, as a massive production of vacancies and interstitials. In case of sufficient availability of pure $\mathrm{Al}$ and $\mathrm{Ni}$, ignition takes place. We believe that these findings illustrate the necessity to build better models for dealing with nanolaminate atomistic structures in relation with their experimental deposition conditions.

${ }^{1}$ C. Rossi, K. Zhang, D. Esteve, P. Alphonse, P. Tailhades, and C. Vahlas, J. Microelectromech. Syst. 16(4), 919-931 (2007).

${ }^{2}$ H. Pezous, C. Rossi, M. Sanchez, F. Mathieu, X. Dollat, S. Charlot, and V. Conedera, J. Phys. Chem. Solids 71(2), 75-79 (2010).

${ }^{3}$ H. Pezous, C. Rossi, M. Sanchez, F. Mathieu, X. Dollat, S. Charlot, L. Salvagnac, and V. Conedera, Sens. Actuators, A 159(2), 157-167 (2010).

${ }^{4}$ K. L. Zhang, C. Rossi, M. Petrantoni, and N. Mauran, J Microelectromech. Syst. 17(4), 832-836 (2008).

${ }^{5}$ R. W. Armstrong, B. Baschung, D. W. Booth, and M. Samirant, Nano Lett. 3(2), 253-255 (2003).

${ }^{6}$ B. S. Bockmon, M. L. Pantoya, S. F. Son, B. W. Asay, and J. T. Mang, J. Appl. Phys. 98(6), 064903 (2005).

${ }^{7}$ A. Duckham, S. J. Spey, J. Wang, M. E. Reiss, T. P. Weihs, E. Besnoin, and O. M. Knio, J. Appl. Phys. 96(4), 2336-2342 (2004).

${ }^{8}$ D. S. Moore, S. E. Son, and B. W. Asay, Propellants Explos., Pyrotech. 29(2), 106-111 (2004)
${ }^{9}$ Y. Kawamura, T. Shoji, and Y. Ohno, J. Non-Cryst. Solids 317(1-2), 152-157 (2003).

${ }^{10}$ C. J. Morris, B. Mary, E. Zakar, S. Barron, G. Fritz, O. Knio, T. P. Weihs, R. Hodgin, P. Wilkins, and C. May, J. Phys. Chem. Solids 71(2), 84-89 (2010).

${ }^{11}$ J. Wang, E. Besnoin, A. Duckham, S. J. Spey, M. E. Reiss, O. M. Knio, M. Powers, M. Whitener, and T. P. Weihs, Appl. Phys. Lett. 83(19), 3987-3989 (2003).

${ }^{12}$ Y. Q. Yang, Z. Y. Sun, S. F. Wang, and D. D. Dlott, J. Phys. Chem. B 107(19), 4485-4493 (2003).

${ }^{13}$ C. Rossi, A. Esteve, and P. Vashishta, J. Phys. Chem. Solids 71(2), 57-58 (2010).

${ }^{14}$ N. A. Manesh, S. Basu, and R. Kumar, Combust. Flame 157(3), 476-480 (2010).

${ }^{15}$ M. Petrantoni, C. Rossi, L. Salvagnac, V. Conedera, A. Esteve, C. Tenailleau, P. Alphonse, and Y. J. Chabal, J. Appl. Phys. 108(8), 084323 (2010).

${ }^{16}$ E. L. Dreizin, Prog. Energy Combust. Sci. 35(2), 141-167 (2009).

${ }^{17}$ K. J. Blobaum, A. J. Wagner, J. M. Plitzko, D. Van Heerden, D. H. Fairbrother, and T. P. Weihs, J. Appl. Phys. 94(5), 2923-2929 (2003).

${ }^{18}$ K. J. Blobaum, D. Van Heerden, A. J. Gavens, and T. P. Weihs, Acta Mater. 51(13), 3871-3884 (2003).

${ }^{19}$ A. J. Gavens, D. Van Heerden, A. B. Mann, M. E. Reiss, and T. P. Weihs, J. Appl. Phys. 87(3), 1255-1263 (2000).

${ }^{20}$ G. A. Lopez, S. Sommadossi, P. Zieba, W. Gust, and E. J. Mittemeijer, Mater. Chem. Phys. 78(2), 459-463 (2003).

${ }^{21}$ F. Baras and O. Politano, Phys. Rev. B 84(2), 024113 (2011).

${ }^{22}$ E. Besnoin, S. Cerutti, O. M. Knio, and T. P. Weihs, J. Appl. Phys. 92(9), 5474-5481 (2002).

${ }^{23}$ M. Petrantoni, A. Hemeryck, J. M. Ducere, A. Esteve, C. Rossi, M. D. Rouhani, D. Esteve, and G. Landa, J. Phys. Chem. Solids 71(2), 130-133 (2010).

${ }^{24}$ A. Arranz and C. Palacio, Thin Solid Films 317(1-2), 55-58 (1998),

${ }^{25}$ T. S. Dyer, Z. A. Munir, and V. Ruth, Scr. Metall. Mater. 30(10), 1281-1286 (1994).

${ }^{26}$ J. Wang, E. Besnoin, O. M. Knio, and T. P. Weihs, Acta Mater. 52(18), 5265-5274 (2004).

${ }^{27}$ S. Zhao, T. C. Germann, and A. Strachan, Phys. Rev. B 76(1), 014103 (2007).

${ }^{28}$ S. J. Zhao, T. C. Germann, and A. Strachan, J. Chem. Phys. 125(16), 164707 (2006).

${ }^{29}$ S. Zhao, T. C. Germann, and A. Strachan, Phys. Rev. B 76, 104105 (2007).

${ }^{30}$ F. Shimojo, A. Nakano, R. K. Kalia, and P. Vashishta, Appl. Phys. Lett. 95(4), 043114 (2009).

${ }^{31}$ L. Alawieh, O. M. Knio and T. P. Weihs, J. Appl. Phys. 110(1), 013509 (2011).

${ }^{32}$ S. Jayaraman, A. B. Mann, M. Reiss, T. P. Weihs, and O. M. Knio, Combust. Flame 124(1-2), 178-194 (2001).

${ }^{33}$ G. Kresse and J. Furthmuller, Comput. Mater. Sci. 6(1), 15-50 (1996).

${ }^{34}$ G. Kresse and J. Furthmuller, Phys. Rev. B 54(16), 11169-11186 (1996).

${ }^{35}$ G. Kresse and J. Hafner, Phys. Rev. B 47(1), 558-561 (1993).

${ }^{36}$ G. Kresse and J. Hafner, Phys. Rev. B 49(20), 14251-14269 (1994).

${ }^{37}$ J. P. Perdew and A. Zunger, Phys. Rev. B 23(10), 5048-5079 (1981).

${ }^{38}$ P. E. Blochl, Phys. Rev. B 50(24), 17953-17979 (1994).

${ }^{39}$ G. Kresse and D. Joubert, Phys. Rev. B 59(3), 1758-1775 (1999).

${ }^{40}$ N. S. Weingarten, W. D. Mattson, A. D. Yau, T. P. Weihs, and B. M. Rice, J. Appl. Phys. 107(9), 093517 (2010).

${ }^{41}$ O. Politano, F. Baras, A. S. Mukasyan, S. G. Vadchenko, and A. S. Rogachev, Surf. Coat. Technol. 215, 485-492 (2013).

${ }^{42}$ H. Y. Kim, D. S. Chung, and S. H. Hong, Mater. Sci. Eng., A 396(1-2), 376-384 (2005).

${ }^{43}$ M. J. Cherukara, K. G. Vishnu, and A. Strachan, Phys. Rev. B 86(7), 075470 (2012). 